Open Access

\title{
The treatment of crigler-najjar syndrome by blue light as explained by resonant recognition model
}

\author{
Irena $\operatorname{Cosic}^{1,2^{*}}$ and Drasko Cosic $^{2}$
}

\author{
* Correspondence: \\ irenacosic@me.com \\ ${ }^{1}$ RMIT University, Melbourne, VIC, \\ Australia \\ ${ }^{2}$ AMALNA Consulting, Black Rock, \\ VIC, Australia
}

\begin{abstract}
Background: The Crigler-Najjar syndrome is extremely rare genetic disease, that is manifested by severe jaundicedue to lack of UDP glucuronosyltransferase 1-A1 (UDP) activity. The main treatment is to use the blue lightphototherapy, during the prolong time, during the day every day.

Methods: Here, we analyzed human UDP's correlation with the blue light phototherapy using the nonlinear physico-mathematical model: Resonant Recognition Model (RRM), which proposes that protein activation is electromagnetic in nature within the frequency range of infrared and visible light.

Results: We found that human UDP's are characterized by specific RRM frequency that is related to the blue light radiation. This could be the explicit explanation, why phototherapy with the blue light could replace lack of UDP activity.

Conclusion: However, the blue light treatment is less effective with ageing, due to decrease of the blue lightpenetration through skin. Thus, there is a need for alternative treatments. Here, we propose to design de-novopeptide, using this specific RRM frequency. Such peptide, according to RRM, is proposed to have the samebiological function as UDP glucuronosyltransferase 1-A1 and thus can be used for alternative treatment of Crigler-Najjar syndrome.
\end{abstract}

Keywords: Crigler-Najjar syndrome, Resonant Recognition Model, Phototherapy, Bioactive peptide design, Macromolecular interaction

\section{Background}

The Crigler-Najjar syndrome is extremely rare genetic disease affecting the metabolisms of bilirubin, resulting in a form of non-hemolytic jaundice [1]. This disease is caused by lack of expression of UDP glucuronosyltransferase 1-A1. Hence, there is no response to treatment with phenobarbital. The only available treatment is phototherapy, which involves radiation of patients with the blue light for an extensive time every day, usually whole night. Similar treatment is used for jaundice in new born babies. However, the blue light treatment is fully effective only with babies and youngsters, as with older people the blue light skin penetration is decreasing. Thus, there is a need for alternative treatments for Crigler-Najjar syndrome.

Here, we have investigated: how and why, the specific blue light radiation can mimic activity of UDP glucuronosyltransferase 1-A1. For that purpose, we used Resonant

(c) The Author(s); licensee Springer on behalf of EPJ. 2016 Open Access This article is distributed under the terms of the Creative Commons Attribution 4.0 International License (http://creativecommons.org/licenses/by/4.0/), which permits unrestricted use, distribution, and reproduction in any medium, provided you give appropriate credit to the original author(s) and the source, provide a link to the Creative Commons license, and indicate if changes were made. 
Recognition Model (RRM) [2-4], which is nonlinear physico-mathematical model, proposing that protein activities and interactions are electromagnetic in nature and are at the specific frequency for each biological function [2-6]. We found that specific RRM frequency for UDP glucuronosyltransferase 1-A1biological function is within the blue light frequency range. This finding explicitly explains, why the blue light can mimic and replace activity of UDP glucuronosyltransferase 1-A1. In addition, using this specific frequency, we designed de-novo peptide that is, according to RRM [2-4], proposed to have the same biological function as UDP glucuronosyltransferase 1-A1. Such peptide could be used for treatment of Crigler-Najjar syndrome.

\section{Methods}

\section{Resonant recognition model}

The RRM postulates that protein interactions entail a mechanism of resonant energy transfer between involved molecules at the frequency specific for each observed function/interaction [2-4]. This proposal is based on the findings that certain periodicities within the distribution of energy of delocalized electrons along a protein molecule are critical for protein biological function and/or interaction with their targets [2-4]. If charge transfer through these macromolecules is introduced, then charge moving through macromolecular backbone can produce electromagnetic radiation, absorption and resonance with spectral characteristics corresponding to the energy distribution [2-6].

The RRM has been well explained in our earlier publications [7] with the following:

"The RRM enables the calculation of these spectral characteristics, by assigning each amino acid a physical parameter representing the energy of delocalized electrons of each amino acid. Comparing Fourier spectra for this energy distributions by using cross-spectral function, it has been found that proteins sharing the same biological function/interaction share the same periodicity (frequency) within energy distribution along the macromolecule [2-4]. Furthermore, it has been shown that interacting proteins and their targets share the same characteristic frequency, but have opposite phase at characteristic frequency $[2-4,8]$. Thus, it has been proposed that the RRM frequencies characterize, not only a general function, but also a recognition and interaction between the particular macromolecule and its target, which then can be considered to be resonant recognition. This could be achieved with resonant energy transfer between the interacting macromolecules through oscillations of a physical field, which is electromagnetic in nature. Since there is evidence that proteins and DNA have certain conducting or semi-conducting properties, a charge moving through the macromolecular backbone and passing different energy stages, caused by different amino acid or nucleotide side groups, can produce sufficient conditions for a specific electromagnetic radiation or absorption. The frequency ranges of this field depend on the charge velocity. The RRM proposes that the charge is travelling through the macromolecular backbone at the estimated velocity of $7.87 \times 10^{5} \mathrm{~m} / \mathrm{s}[2,3]$. For this velocity and with the distance between amino acids in a protein molecule of $3.8 \AA$, the frequency of protein interactions was estimated to be 
in the range between $10^{13} \mathrm{~Hz}$ and $10^{15} \mathrm{~Hz}$. Therefore, the estimated frequency range for both amino acid and nucleotide macromolecules includes infra-red, visible and ultra-violet light. To support this idea, we compared our computational predictions with a number of published experimental results $[2-4,8]$ :

- Laser light growth promotion of cells, by using the particular frequencies of light to produce the similar effect to that of growth factor proteins;

- Chymotrypsin activation (increase of enzyme activity) achieved by laser light radiation in a range of $850-860 \mathrm{~nm}$;

- Activation of highly homologous plant photoreceptors which, although being very homologous, absorb different wavelengths of light;

- Photo activated proteins, e.g. rhodopsin, flavodoxin, etc.

These comparisons have shown a strong linear correlation between frequencies, as calculated using the RRM method and experimentally measured characteristic frequencies, with the slope factor of $K=201[2-4,8]$. This finding parallels with the frequency range previously associated with the RRM numerical frequency spectrum that has been calculated from the charge velocities through the protein backbone. This correlation can be represented as following:

$$
\lambda=\mathrm{K} / \text { frrm }
$$

where $\lambda$ is the wavelength of light irradiation in $\mathrm{nm}$, which can influence a particular biological process, frrm is a RRM numerical frequency and $\mathrm{K}$ is coefficient of this linear correlation.

We applied this concept on a number of proteins and DNA examples. The concept has been also experimentally tested by predicting the electromagnetic frequencies for L-Lactate Dehydrogenase [5], where by radiating L-Lactate Dehydrogenase with predicted calculated electromagnetic frequencies the significant change in enzyme activity was achieved. The concept has also been tested independently on experimental measurements of photon emission from dying melanoma cells [9], on photon emission from lethal and non-lethal Ebola strains [10], as well as on classic signaling pathway, JAK-STAT, traditionally composed of nine sequential protein interactions [11].

Keeping all this in mind, we propose that the RRM concept is excellent predictor for proteins and DNA selective interactions, biological processes and pathways in living cells" [7].

In addition, once the characteristic frequency for biological function of the protein has been identified, it is possible to design new proteins/peptides with these desired frequency components and consequently with this desired biological function. Such approach has been already successfully applied and experimentally tested in design of FGF analogue [2-4, 12], HIV envelope protein analogue [2-4, 13] and peptide to mimic myxoma virus oncolytic function $[14,15]$.

\section{Sequences}

In our study we used six HUMAN UDP-glucuronosyltransferase proteins and bilirubin-inducible fluorescent protein UnaG, that binds unconjugated bilirubin with 
high affinity. All of these protein sequences have been collected from UNIPROT database, as listed below:

○ P22309|UD11_HUMAN UDP-glucuronosyltransferase 1-1 OS = Homo sapiens $\mathrm{GN}=\mathrm{UGT} 1 \mathrm{~A} 1 \mathrm{PE}=1 \mathrm{SV}=1$

○ P35503|UD13_HUMAN UDP-glucuronosyltransferase 1-3 OS = Homo sapiens $\mathrm{GN}=\mathrm{UGT} 1 \mathrm{~A} 3 \mathrm{PE}=1 \mathrm{SV}=1$

○ P22310|UD14_HUMAN UDP-glucuronosyltransferase 1-4 OS = Homo sapiens $\mathrm{GN}=\mathrm{UGT} 1 \mathrm{~A} 4 \mathrm{PE}=1 \mathrm{SV}=1$

○ P35504|UD15_HUMAN UDP-glucuronosyltransferase 1-5 OS = Homo sapiens $\mathrm{GN}=\mathrm{UGT} 1 \mathrm{~A} 5 \mathrm{PE}=2 \mathrm{SV}=1$

○ P19224|UD16_HUMAN UDP-glucuronosyltransferase 1-6 OS = Homo sapiens $\mathrm{GN}=\mathrm{UGT} 1 \mathrm{~A} 6 \mathrm{PE}=1 \mathrm{SV}=2$

○ O60656|UD19_HUMAN UDP-glucuronosyltransferase 1-9 OS = Homo sapiens $\mathrm{GN}=\mathrm{UGT} 1 \mathrm{~A} 9 \mathrm{PE}=1 \mathrm{SV}=1$

○ P0DM59|UNAG_ANGJA Bilirubin-inducible fluorescent protein UnaG $\mathrm{OS}=$ Anguilla japonica $\mathrm{PE}=1 \mathrm{SV}=1$.

\section{Results and Discussion}

We have analyzed six HUMAN UDP-glucuronosyltransferase proteins using the RRM and it has been revealed that the common frequency for all analyzed sequences is at frequency of $f=0.3799 \pm 0.0072$, as presented in Fig. 1 .

To make sure that this frequency is related to UDP function in bilirubin metabolism, we have also compared these six human UDP's with beta-barrel protein (angja), that binds bilirubin with high affinity. The result is the more prominent peak at frequency of $f=0.3799 \pm 0.0072$, as presented in Fig. 2. This confirms that frequency of $\mathrm{f}=0.3799 \pm 0.0072$ is common to UDP's and angja proteins.

Thus, we can propose that this characteristic frequency is critical for metabolism of bilirubin. According to RRM this numerical frequency is related to electromagnetic radiation range between 519 and $539 \mathrm{~nm}$, calculated as per formula above and encompass with the blue light spectrum, as presented in Fig. 3.

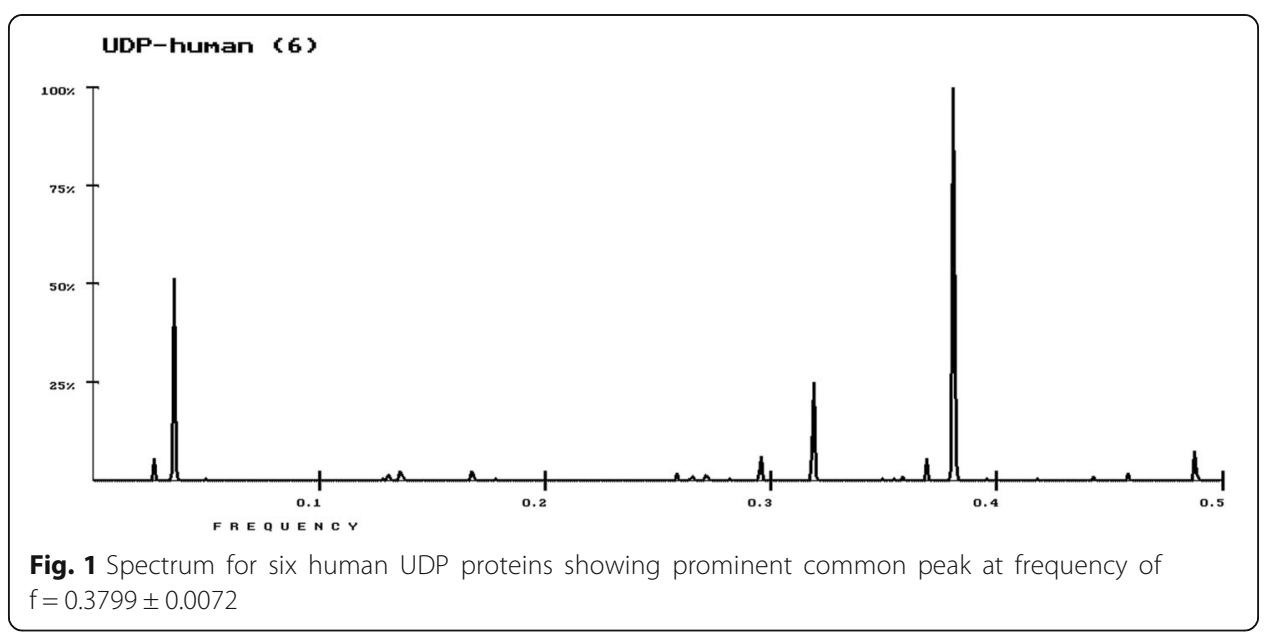




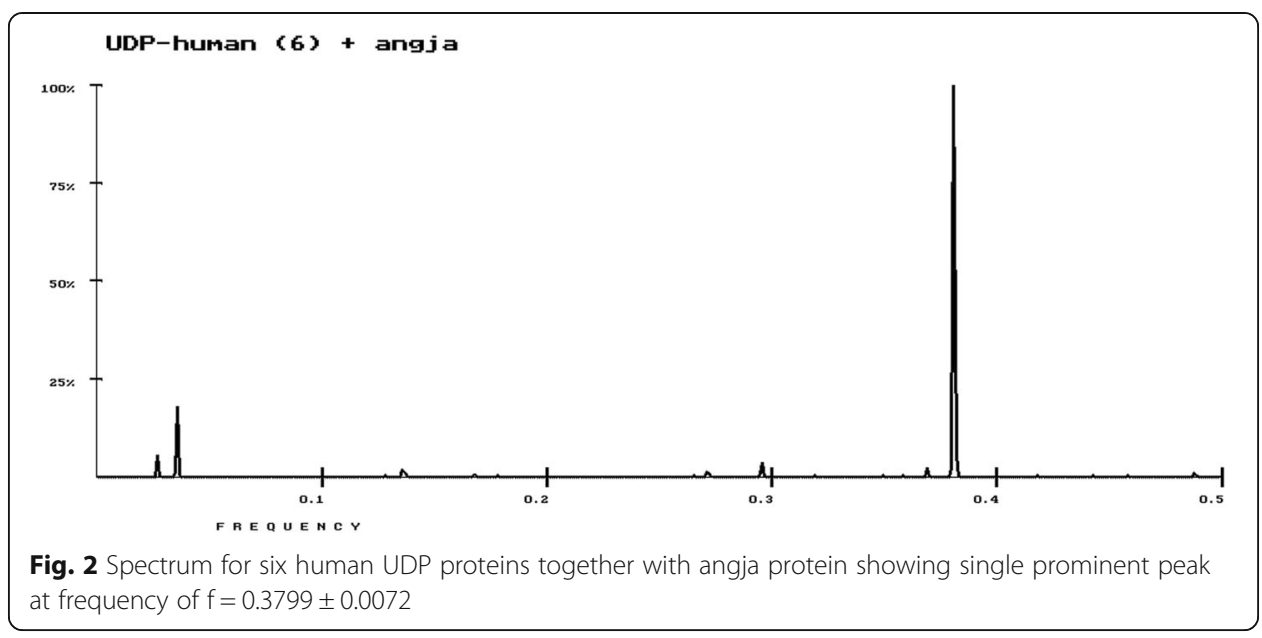

Here, we found using the RRM, that characteristic frequency for human UDP's function in bilirubin metabolism is encompassing the blue light radiation. This is crucial finding, that could be the explicit explanation, why phototherapy with the blue light could replace lack of UDP activity. It is for the first time that the RRM could be used in calculating the characteristic frequencies of phototherapy for specific treatments.

The blue light phototherapy for the Crigler-Najjar syndrome is less effective in grownup patients, as the blue light penetration through the skin is diminishing with ageing of the patient. Thus, there is a need for alternative approach to treatment of Crigler-Najjar syndrome. We propose to utilize the RRM approach to design peptides that would have only the established characteristic frequency related to bilirubin metabolism. Such peptide potentially can have UDP activity and thus can be used in treatment of Crigler-Najjar syndrome.

Using the RRM we have designed the 20 amino acids sequence that has only frequency of $f=0.3799$ and phase same as within UD11_HUMAN UDP-glucuronosyltransferase protein sequence. The designed sequence is: RLDYHDECTNDKADLRQEDP.

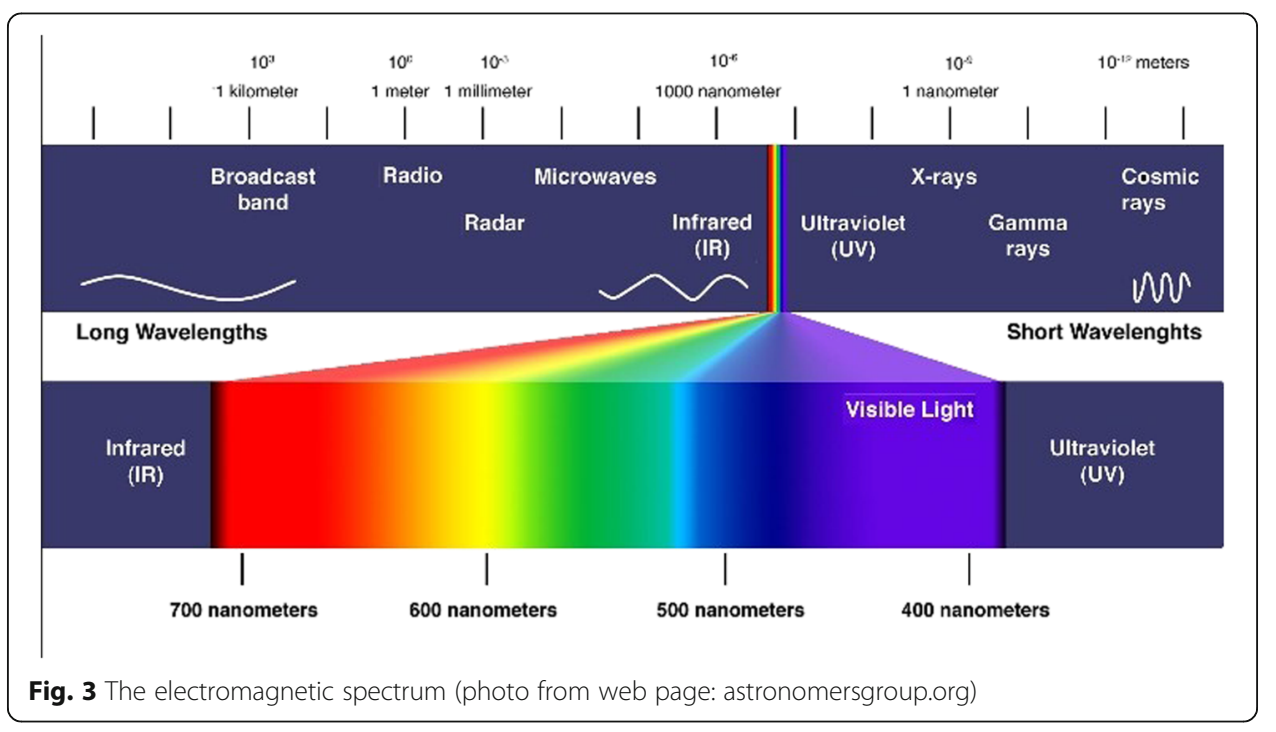


We propose that this designed peptide could be used in treatment of Crigler-Najjar syndrome.

\section{Conclusion}

The lack of activity of UDP proteins in Crigler-Najjar syndrome is replaced by the blue light phototherapy treatment. Here for the first time, we found the biophysical relationship between activity of UDP proteins and the blue light using the nonlinear physico-mathematical model: Resonant Recognition Model (RRM), which proposes that protein activation is electromagnetic in nature within the frequency range of infrared and visible light. We found that human UDP's are characterized by specific RRM frequency that is related to the blue light. This could be the explicit explanation, why phototherapy with the blue light could replace lack of UDP activity.

However, the blue light treatment is fully effective only with babies and youngsters, as with older people the blue light skin penetration is decreasing. Thus, using this specific RRM frequency, we designed de-novo peptide that is, according to RRM, proposed to have the same biological function as UDP glucuronosyltransferase 1-A1. Such peptide can be used for treatment of Crigler-Najjar syndrome.

\section{Abbreviations \\ angja: Bilirubin-inducible fluorescent protein UnaG; DNA: DeoxyriboNucleic acid; FGF: Fibroblast growth factor; HIV: Human immunodeficiency virus; RRM: Resonant Recognition Model; UDP: UDP-glucuronosyltransferase}

\section{Acknowledgments}

The current research work is funded by AMALNA Consulting, registered consulting and research company, Australia.

\section{Authors' contributions}

IC and DC have equal contributions. Both authors read and approved the final manuscript.

\section{Competing interests}

The authors declare that they have no competing interests.

Received: 20 October 2016 Accepted: 4 November 2016

Published online: 18 November 2016

\section{References}

1. Jansen PL. Diagnosis and management of Crigler-Najjar syndrome. Eur J Pediatr. 1999;158:89-94. doi:10.1007/PL00014330.

2. Cosic I. Macromolecular Bioactivity: Is it Resonant Interaction between Macromolecules?-Theory and Applications. IEEE Trans Biomed Eng. 1994;41:1101-14.

3. Cosic I. Virtual spectroscopy for fun and profit. Biotechnology. 1995;13:236-8.

4. Cosic I. The Resonant Recognition Model of Macromolecular Bioactivity: Theory and Applications. Basel: Birkhauser Verlag; 1997.

5. Vojisavljevic V, Pirogova E, Cosic I. The Effect of Electromagnetic Radiation (550 nm-850nm) on I-Lactate Dehydrogenase Kinetics. Int J Radiat Biol. 2007;83:221-30.

6. Cosic I, Cosic D, Lazar K: Is it possible to predict electromagnetic resonances in proteins, DNA and RNA? Nonlinear Biomed Phys. 2015; 3, doi:10.1140/s40366-015-0020-6.

7. Cosic I, Cosic D, Lazar K. Environmental Light and Its Relationship with Electromagnetic Resonances of Biomolecular Interactions, as Predicted by the Resonant Recognition Model. Int J Environ Res Public Health. 2016; 13(7):647. doi:10.3390/ijeprh13070647.

8. Cosic I, Cosic D, Lazar K. Analysis of Tumor Necrosis Factor Function Using the Resonant Recognition Model. Cell Biochem Biophys. 2015;74(2):175-80. doi:10.1007/s12013-015-0716-3.

9. Dotta BT, Murugan NJ, Karbowski LM, Lafrenie RM, Persinger MA: Shifting wavelength of ultraweak photon emissions from dying melanoma cells: their chemical enhancement and blocking are predicted by Cosic's theory of resonant recognition model for macromolecules. Naturwissenschaften 2014, 101(2), doi:10.1007/s00114-013-1133-3.

10. Murugan NJ, Karbowski LM, Persinger MA. Cosic's Resonance Recognition Model for Protein Sequences and Photon Emission Differentiates Lethal and Non-Lethal Ebola Strains: Implications for Treatment. Open J Biophys. 2014:5:35.

11. Karbowski LM, Murugan NJ, Persinger MA. Novel Cosic resonance (standing wave) solutions for components of the JAK-STAT cellular signalling pathway: A convergence of spectral density profiles. FEBS Open Bio. 2015;5:245-50

12. Cosic I, Drummond AE, Underwood JR, Hearn MTW. In vitro inhibition of the actions of basic FGF by a novel 16 amino acid peptides. Mol Cell Biochem. 1994;130:1-9. 
13. Krsmanovic V, Biquard JM, Sikorska-Walker M, Cosic I, Desgranges C, Trabaud MA, Whitfield JF, Durkin JP, Achour A, Hearn MT. Investigation into the Cross-reactivity of Rabbit Antibodies Raised against Nonhomologous Pairs of Synthetic Peptides Derived from HIV-1 gp120 proteins. J Peptide Res. 1998;52(5):410-2.

14. Istivan T, Pirogova E, Gan E, Almansour N, Coloe P, Cosic I. Biological effects of a De Novo designed myxoma virus peptide analogue: Evaluation of cytotoxicity on tumor cells. Public Library Sci (PLoS) ONE. 2011;6(9):1-10.

15. Almansour N, Pirogova E, Coloe P, Cosic I, Istivan T. Investigation of cytotoxicity of negative control peptides versus bioactive peptides on skin cancer and normal cells: a comparative study. Future Med Chem. 2012;4(12):1553-65.

Submit your manuscript to a SpringerOpen ${ }^{\circ}$ journal and benefit from:

- Convenient online submission

- Rigorous peer review

- Immediate publication on acceptance

- Open access: articles freely available online

- High visibility within the field

- Retaining the copyright to your article

Submit your next manuscript at $>$ springeropen.com 